R. ZYBAŁA*\#, K. MARS**, A. MIKUŁA**, J. BOGUSŁAWSKI***, G. SOBOŃ***, J. SOTOR***,

M. SCHMIDT****, K. KASZYCA****, M. CHMIELEWSKI****, L. CIUPIŃSKI*, K. PIETRZAK****

\title{
SYNTHESIS AND CHARACTERIZATION OF ANTIMONY TELLURIDE FOR THERMOELECTRIC AND OPTOELECTRONIC APPLICATIONS
}

\begin{abstract}
Antimony telluride $\left(\mathrm{Sb}_{2} \mathrm{Te}_{3}\right)$ is an intermetallic compound crystallizing in a hexagonal lattice with $R$ - $3 m$ space group. It creates a close packed structure of an $A B C A B C$ type. As intrinsic semiconductor characterized by excellent electrical properties, $\mathrm{Sb}_{2} \mathrm{Te}_{3}$ is widely used as a low-temperature thermoelectric material. At the same time, due to unusual properties (strictly connected with the structure), antimony telluride exhibits nonlinear optical properties, including saturable absorption. Nanostructurization, elemental doping and possibilities of synthesis $\mathrm{Sb}_{2} \mathrm{Te}_{3}$ in various forms (polycrystalline, single crystal or thin film) are the most promising methods for improving thermoelectric properties of $\mathrm{Sb}_{2} \mathrm{Te}_{3}$.Applications of $\mathrm{Sb}_{2} \mathrm{Te}_{3}$ in optical devices (e.g. nonlinear modulator, in particular saturable absorbers for ultrafast lasers) are also interesting. The antimony telluride in form of bulk polycrystals and layers for thermoelectric and optoelectronic applications respectively were used. For optical applications thin layers of the material were formed and studied. Synthesis and structural characterization of $\mathrm{Sb}_{2} \mathrm{Te}_{3}$ were also presented here. The anisotropy (packed structure) and its influence on thermoelectric properties have been performed. Furthermore, preparation and characterization of $\mathrm{Sb}_{2} \mathrm{Te}_{3}$ thin films for optical uses have been also made.
\end{abstract}

Keywords: antimony telluride, thermoelectric materials, thin films, PVD magnetron sputtering, topological insulator.

\section{Introduction}

Thermoelectric materials are usually described by the thermoelectric figure of merit $Z T$ that is closely related to energy conversion efficiency from heat into electricity. The ZT value increases when the Seebeck coefficient and the electrical conductivity increases and the thermal conductivity decreases [1]. Thermoelectric module build from $p$ - and $n$ - type materials allowed to direct energy conversion, but due to low efficiency of commercially available modules [2] researchers try to modify properties of know materials and in the same time search for a new one. Antimony telluride $\mathrm{Sb}_{2} \mathrm{Te}_{3}$ has been commonly applied for many years as a low-temperature thermoelectric material, because of its relatively high value of $Z T$ parameter (close to $\sim 1$ ). These good thermoelectric properties of $\mathrm{Sb}_{2} \mathrm{Te}_{3}$ stem from its crystallographic structure.

Due to this crystallography it is also possible to manage the compound macroscopic properties by structurization of the polycrystalline material [3]. The spark plasma sintering (SPS) when used for compacting thermoelectric materials can prevent grain size growth and increase ZT by decreasing thermal conductivity $[4,5]$. The process can be used to obtain high density samples that can be used to construct high efficiency thermoelectric modules.
Recently, topological insulator properties have been discovered in $\mathrm{Sb}_{2} \mathrm{Te}_{3}$ compound [6]. Further this led researches to detect broadband nonlinear optical properties, including nonlinear absorption and refraction $[7,8]$. This creates a possibility to use it as a saturable absorber for mode-locked and Q-switched fibre lasers [9,10], for nonlinear beam shaping [11], and to obtain super-resolution effect in nano-optics [12]. Another crucial advantage is its broadband operation characteristic, allowing the use in devices working in various spectral ranges in visible light and infrared.

\section{Experimental}

Solid $\mathrm{Sb}_{2} \mathrm{Te}_{3}$ was obtained by alloying the elementary powders in quartz ampules sealed under vacuum (at $950 \mathrm{~K}$ for 1 hour and next slowly cooled down) in the rocking furnace. Subsequently, the ingots have been mechanically milled (WC

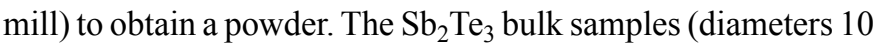
and $50 \mathrm{~mm}$ ) were formed by SPS, at the temperature of $700 \mathrm{~K}$ and under pressure $40 \mathrm{MPa}$ in a graphite die.

Material for PVD (Physical Vapor Deposition) target was synthesized for $1 \mathrm{~h}$ at $970 \mathrm{~K}$. Then the material was crushed

\footnotetext{
* WARSAW UNIVERSITY OF TECHNOLOGY, FACULTY OF MATERIALS SCIENCE AND ENGINEERING, 141 WOLOSKA, WARSAW 02-507, POLAND

** AGH UNIVERSITY OF SCIENCE AND TECHNOLOGY, AL. A. MICKIEWICZA 30, 30-059 KRAKÓW, POLAND

*** WROCLAW UNIVERSITY OF SCIENCE AND TECHNOLOGY, FACULTY OF ELECTRONICS, WROCLAW, POLAND

**** INSTITUTE OF ELECTRONIC MATERIALS TECHNOLOGY, WARSAW, POLAND

\# Corresponding author: Rafal.Zybala@inmat.pw.edu.pl
} 
and milled in anhydrous alcohol. After alcohol evaporation the powder was sifted and particles in the range from 60 to $90 \mu \mathrm{m}$ were chosen for further preparation. The $\mathrm{Sb}_{2} \mathrm{Te}_{3}$ target with dimensions: diameter $50 \mathrm{~mm}$, thickness $3 \mathrm{~mm}$ was compacted by SPS at the maximum temperature below $725 \mathrm{~K}$, pressure $40 \mathrm{MPa}$ and time $30 \mathrm{~min}$.

Thin films of antimony telluride were produced in a typical batch-type vacuum deposition system using a diffusion pump backed by mechanical pump. $\mathrm{Sb}_{2} \mathrm{Te}_{3}$ layers were obtained with one magnetron with planar target of $50 \mathrm{~mm}$ diameter. The sputtering process was supported by the pulsed power supply generating pulses with the $80 \mathrm{kHz}$ frequency and the group modulation of $2.5 \mathrm{kHz}$. Sputtering of $\mathrm{Sb}_{2} \mathrm{Te}_{3}$ target was conducted under constant conditions of power $(0.03 \mathrm{~kW})$ and current $(0.05 \mathrm{~A})$ at the argon pressure of $0.25 \mathrm{~Pa}$. Layers of varying thicknesses were deposited on substrate plates, 24 by $24 \mathrm{~mm}$, made of glass, and side-polished optical fibres.

The phase composition of the materials was measured by the X-ray diffractometer Philips (PANalytical) X'Pert Pro with Bragg-Brentano geometry. For layers GID (Grazing Incidence Diffraction) technique was used with PANalytical Empyrean diffractometer with parallel beam (under $1^{\circ}$ ) and Euler's holder.

Raman spectroscopy was used to characterize the chemical bonding of the coating. Raman spectra have been recorded using Horiba LabRAM HR800 spectrometer coupled with a $532 \mathrm{~nm}$ Nd-YAG diode laser. Measurements were carried out at several different places of the samples, with following parameters: diffraction grating: 1800 lines/mm, acquisition time $30 \mathrm{sec}$, accumulation 4 .

The structure and chemical composition of the layers were investigated by SEM (Scanning Electron Microscopy). For bulk material there were prepared two kinds of samples with different orientation (perpendicular and parallel) to pressing force direction during SPS sintering. SEM FEI NOVA NANO SEM 200 equipped with EDS analyser from EDAX was used.

Transmission spectrum was measured using Fourier Transform Infrared Spectroscopy (FT-IR). Nonlinear optical properties of $\mathrm{Sb}_{2} \mathrm{Te}_{3}$ thin films were verified by power-dependent transmission change measurement under the influence of a 300-fs laser at $1560 \mathrm{~nm}$ (Menlo T-Light) with $100 \mathrm{MHz}$ repetition rate. The measurement was performed in all-fibre setup [13].

Temperature dependences of thermoelectric properties (thermal and electrical conductivities, Seebeck coefficient) were measured in the temperature range from $300 \mathrm{~K}$ to $550 \mathrm{~K}$. Electrical conductivity was measured by the van der Pauw method, Seebeck coefficient by the standard method and thermal conductivity by the Laser Flash Apparatus (LFA 457 MicroFlash, NETZSCH).

\section{Results and discussion}

The $\mathrm{Sb}_{2} \mathrm{Te}_{3}$ layers prepared by PVD technique mainly consisted of pure $\mathrm{Sb}_{2} \mathrm{Te}_{3}$ phase. Possible existence of some impurities corresponding to $\mathrm{SiO}_{2}$ phase as well as high background can be connected with the influence of the amorphous glass substrate. The widened peeks in XRD patterns can indicate the fine crystalline grain size in the samples after deposition. The results of the XRD measurements can be seen in the diffraction patterns (Fig. 1)

Representative Raman spectroscopy measurements for $\mathrm{Sb}_{2} \mathrm{Te}_{3}$ layer are presented in Fig. 2. Raman spectrum exhibit the representative bands at the 63, 108 (overlapped with 116) and $162 \mathrm{~cm}^{-1}$ which are closely related to $A_{1 \mathrm{~g}}$ and $E_{g}$ modes ( $\mathrm{Sb}$-Te vibrations) of $\mathrm{Sb}_{2} \mathrm{Te}_{3}$ structure [14-16]. The characteristic doublet observed at 116 and $137 \mathrm{~cm}^{-1}$ as well as the band at 89 $\mathrm{cm}^{-1}$ with very low integral intensity can be attributed to the interaction of Te-Te between packages of the antimony telluride. The line at $251 \mathrm{~cm}^{-1}$ should be related to vibration $\mathrm{Sb}-\mathrm{O}$ oxide mode due to surface modification of the short-wavelength laser illumination $[16,17]$.

This signal increase with increasing laser power during measurements. The data from different sample places did not show any differences.
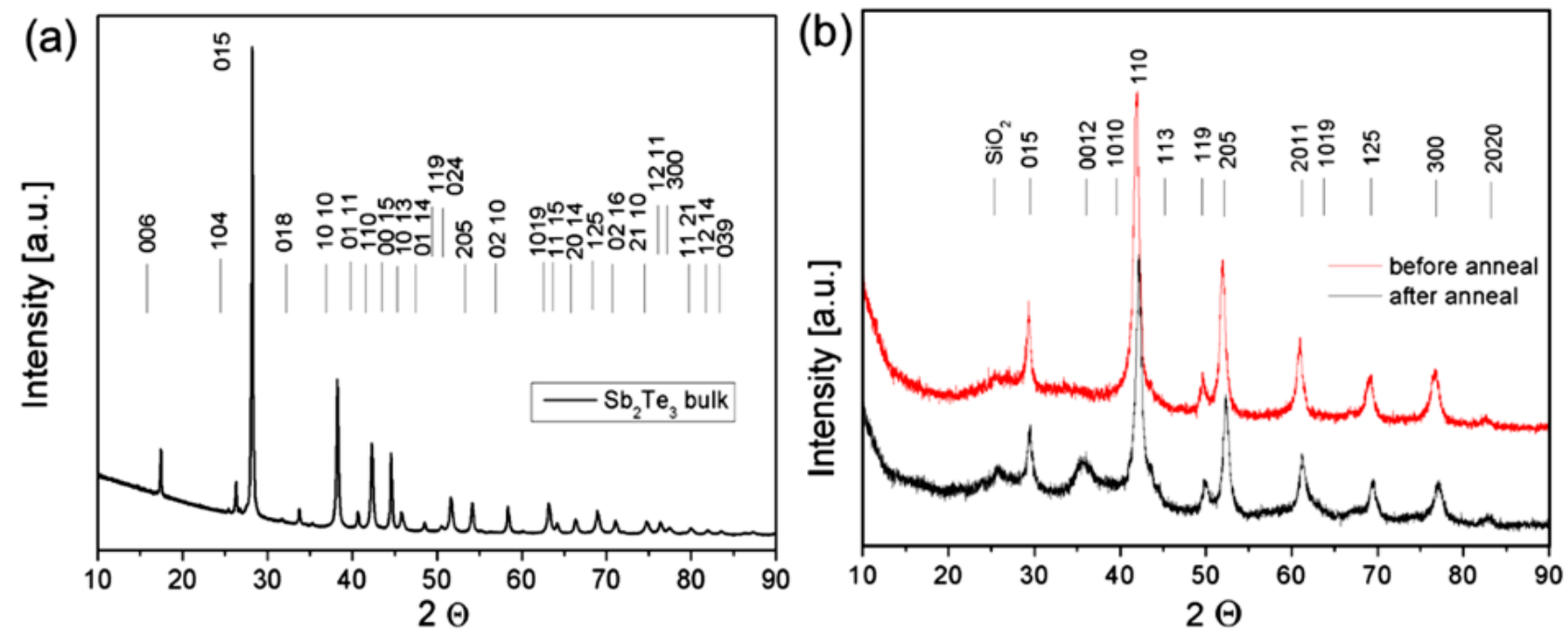

Fig. 1. Diffraction pasterns for (a) $\mathrm{Sb}_{2} \mathrm{Te}_{3}$ and (b) layer prepared by PVD on the laboratory glass 


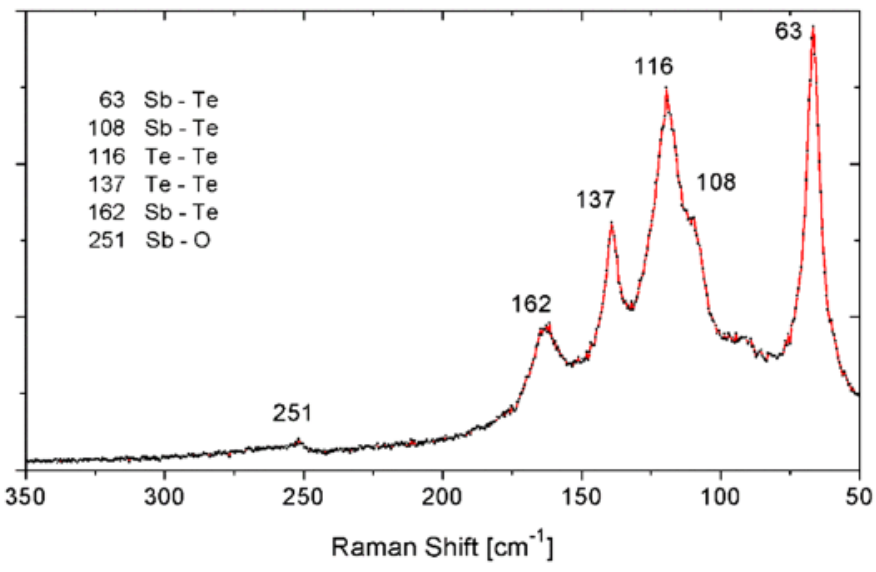

Fig. 2. Raman spectrum for $\mathrm{Sb}_{2} \mathrm{Te}_{3}$ layer

The fracture surface of bulk materials (Fig. 3) proves that after sintering process the material possess the layered structure with layers perpendicular (Fig. 3a) to the pressing force. In the same time the force is parallel to the normal vector to the surface and the $c$ parameter of the elementary cell.
SEM images of the $\mathrm{Sb}_{2} \mathrm{Te}_{3}$ thin layer prepared by PVD technique on laboratory glass are presented in Fig. 3c. The chemical analysis by EDS technique revealed that in analyzed area there are the amounts of $\mathrm{Sb}$ and Te corresponding to the $\mathrm{Sb}_{2} \mathrm{Te}_{3}$ composition. Droplets that can be seen on the surface are the effect of inhomogeneity of the target.

For the transmission spectrum measurement, the thin film was deposited on uncoated calcium fluoride $\left(\mathrm{CaF}_{2}\right)$ window with transmission from visible light up to $8 \mu \mathrm{m}$. The measurement result is presented in Fig. 4. The transmission increases together with wavelength, with values of $56 \%, 71 \%$, and $76 \%$ at $1.56 \mu \mathrm{m}$, $1.96 \mu \mathrm{m}$, and $2.1 \mu \mathrm{m}$, respectively. Wavelengths correspond to three emission bands of the most common near-infrared rare ion dopants in active media for laser emission erbium (operating at $1.56 \mu \mathrm{m})$, thulium $(1.96 \mu \mathrm{m})$ and holmium $(2.1 \mu \mathrm{m})$ [18]. The transmission level indicates a possibility of application of $\mathrm{Sb}_{2} \mathrm{Te}_{3}$ thin film in lasers operating in those spectral regions. The whole spectrum is characterized by a smooth shape.

For the measurement of nonlinear properties, a thin film was deposited on standard single mode fibre connector, which enables the use in all-fibre setups. The measurement revealed
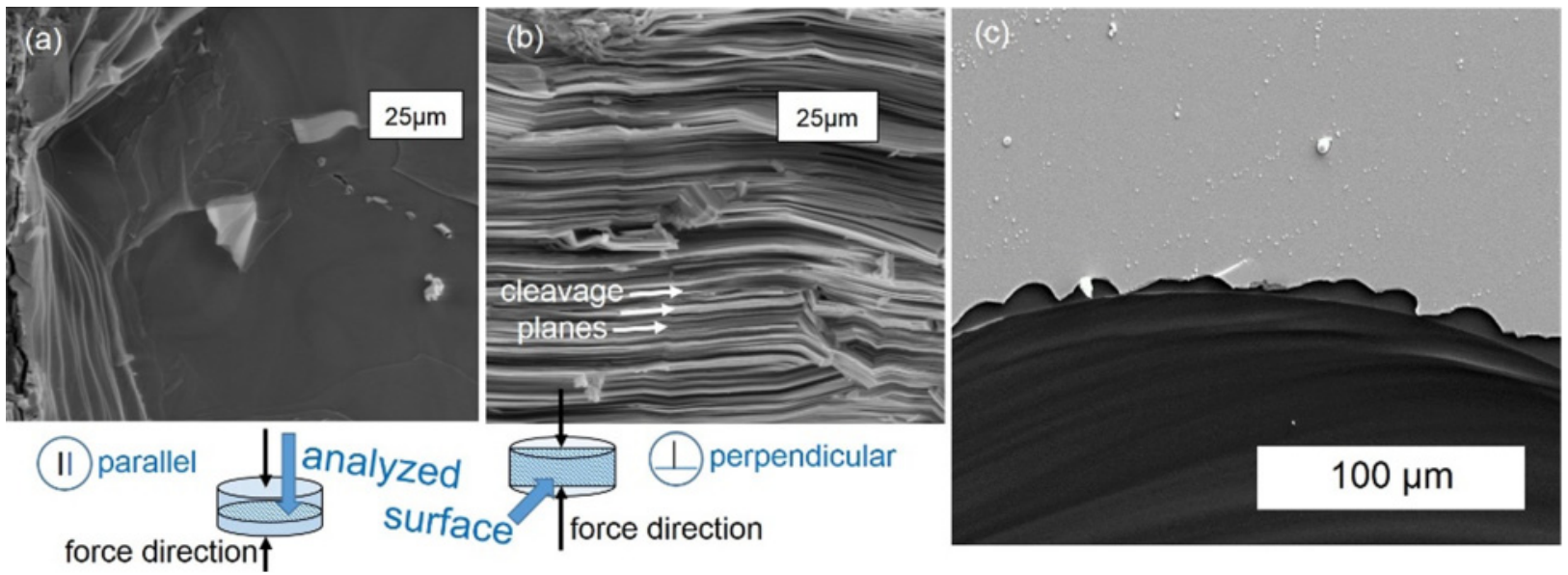

Fig. 3. SEM images of the $\mathrm{Sb}_{2} \mathrm{Te}_{3}$ : bulk samples fracture for different orientation to the pressing force during SPS process: (a) parallel, (b) perpendicular and (c) image of the layer prepared by PVD technique
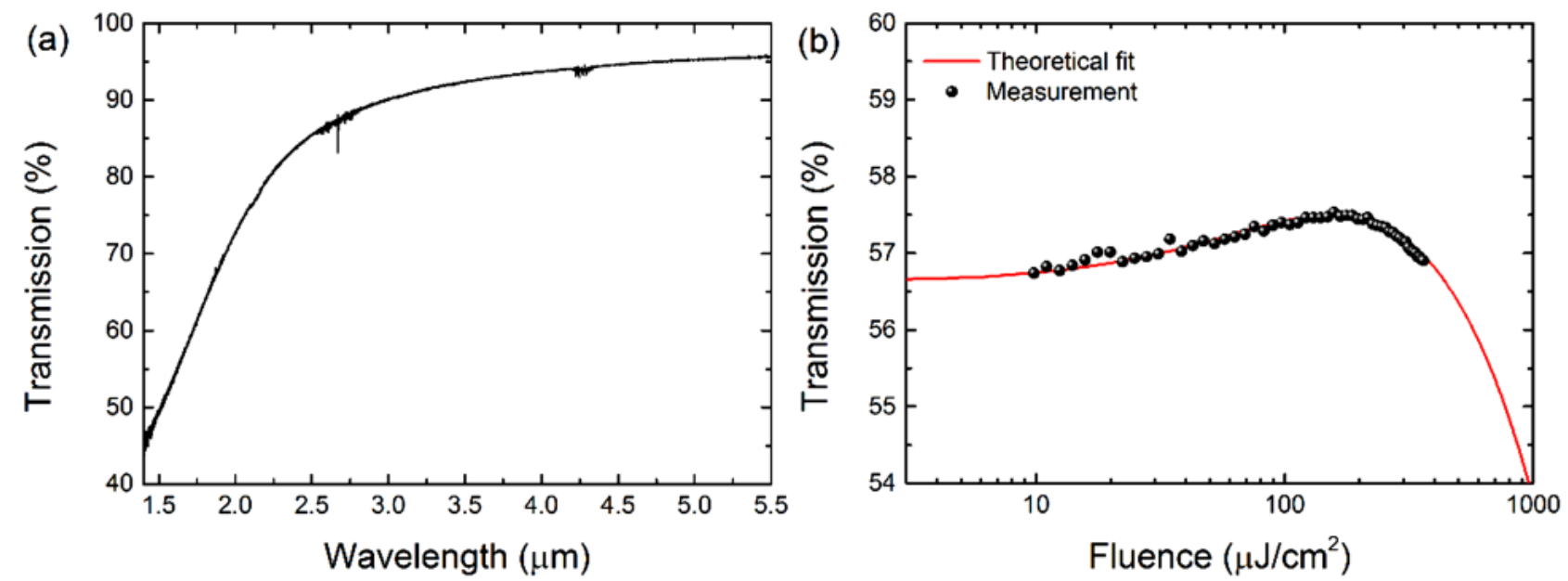

Fig. 4. Optical properties of $\mathrm{Sb}_{2} \mathrm{Te}_{3}$ thin films: (a) transmission spectrum of thin film deposited on $\mathrm{CaF}_{2}$ window, (b) and nonlinear transmission curve of thin film deposited on fibre connector measured at $1.56 \mu \mathrm{m}$ 

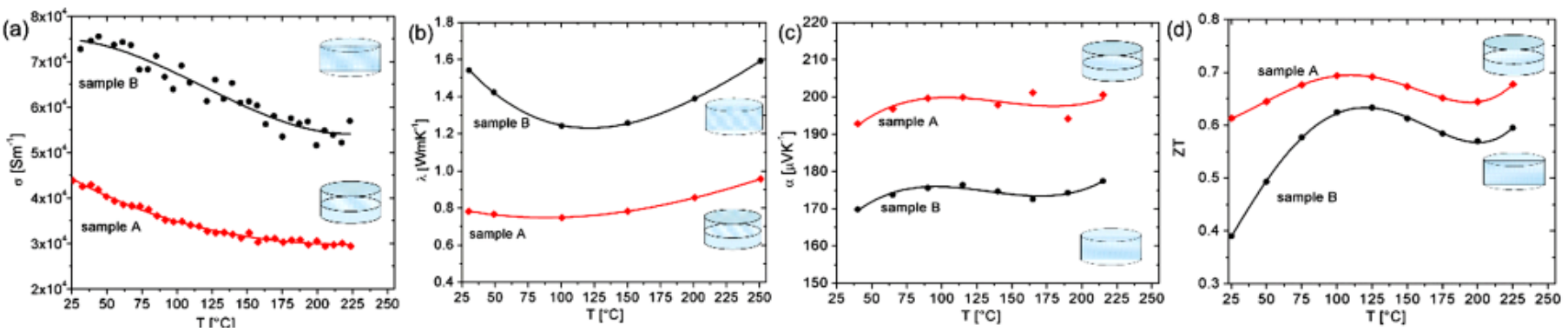

Fig. 5. Thermoelectric properties of the doped $\mathrm{Sb}_{2} \mathrm{Te}_{3}$ along different axis as a temperature function, (a) electrical conductivity, (b) thermal conductivity (c) Seebeck coefficient, (d) ZT parameter

that $\mathrm{Sb}_{2} \mathrm{Te}_{3}$ is characterized by a saturable absorption with low saturation fluence of $50 \mu \mathrm{J} / \mathrm{cm}^{2}$, which stems from high thirdorder nonlinearity. The measured modulation depth of $1 \%$ is limited by the inverse slope in saturable absorption due to the two-photon absorption.

The experiments show that antimony telluride has potential to be used in novel nonlinear optical devices, in particular broadband and versatile saturable absorbers for fibre lasers $[9,10]$.

Graphs presented in Fig. 5 show the measured thermoelectric properties of the prepared bulk thermoelectric doped $\mathrm{Sb}_{2} \mathrm{Te}_{3}$ material as a temperature function along two orientation to pressing force during sintering (parallel and perpendicular). The most significant effect depending on the direction can be seen for the value of the thermal conductivity (Fig. 5b). The differences between two different directions in thermal conductivity is significant and for parallel one is almost two times lower than for perpendicular. The lower thermal conductivity as we know from structural measurements is obtained along $\mathrm{c}$ axis (in most grains). From the other graphs we can also note the dependencies from direction for Seebeck coefficient (Fig. 5c), electrical conductivity (Fig. 5a) and thermoelectric figure of merit $Z T$. The $Z T$ value is evidently higher in parallel direction to pressing force and reach its maximum equal 0.7 at $100^{\circ} \mathrm{C}$ (Fig. $5 \mathrm{~d})$. This analysis indicates significant impact of anisotropy on the thermoelectric properties in antimony telluride.

\section{Conclusions}

The measurement revealed that $\mathrm{Sb}_{2} \mathrm{Te}_{3}$ is characterized by a saturable absorption with a low saturation fluence, which stems from high third-order nonlinearity. Additionally, we have observed the inverse slope in saturable absorption due to the two-photon absorption. The experiments suggest that antimony telluride can be used to develop novel nonlinear optical devices.

The bulk material after sintering process exhibit the layered structure with layers normal vector and the $c$ parameter of the elementary cell parallel to the pressing force during SPS process. This anisotropy strongly influences the value of $Z T$ parameter. The highest $Z T$ value equal 0.7 was reached for $\mathrm{Bi}_{\mathrm{x}} \mathrm{Sb}_{2-\mathrm{x}} \mathrm{Te}_{3}(x=0.5)$ at $100^{\circ} \mathrm{C}$ in the direction parallel to the pressing force.

\section{Acknowledgments}

Work presented in this paper was supported by project no. PBS3/A5/49/2015 (NCBR, Poland). This work has been partially financed as a research projects no. DEC-2014/12/S/ST8/00582 and DEC-2014/13/B/ST7/01699 (NCN, Poland). J.B. acknowledges doctoral fellowship financed by National Science Centre (NCN, Poland) under the grant no. 2016/20/T/ST7/00189.

We acknowledge Dr. Karol Krzempek (Laser \& Fiber Electronics Group, WUST) for his valuable help with FTIR measurements.

\section{REFERENCES}

[1] D.M. Rowe ed.: CRC Handbook of Thermoelectrics, Ch 3 (CRC Press, 1995)

[2] R. Zybała, M. Schmidt, K. Kaszyca et al., J. Electron. Mater. 45 (10), 5223-5231 (2016).

[3] R. Zybala, K.T. Wojciechowski, AIP Conf. Proc. 1449, 393 (2012) doi: 10.1063/1.4731579.

[4] M.J. Kruszewski, R. Zybala, L. Ciupinski, et al., J. Electron. Mater. 45 (3), 1369 (2016)

[5] P. Nieroda, R. Zybala, K.T. Wojciechowski, AIP Conf. Proc. 1449, 199 (2012), doi: 10.1063/1.4731531.

[6] H. Zhang, C.X. Liu, X.L. Qi, et al., Nat. Phys. 5(6), 438-442 (2009).

[7] J. Liu, S. Liu, J. Wei, Appl. Phys. Lett. 97, 261903 (2010).

[8] J. Sotor, G. Sobon, W. Macherzynski, et al., Opt. Mater. Express 4 (1), 1-6 (2014).

[9] J. Boguslawski, G. Sobon, R, Zybala, et al., Opt. Express 23 (22), 29014-29023 (2015).

[10] J. Bogusławski, G. Sobon, K. Tarnowski, et al., Opt. Eng. 55 (8) 081316, (2016).

[11] C.Tan, Q. Wang, X.Fu, Opt. Mater. Express 4(10), 2016-2025(2014).

[12] Wei Jingsong, Optical Nonlinear Absorption and Refraction of Semiconductor Thin Films. In Nonlinear Super-Resolution Nano-Optics and Applications, Springer Berlin Heidelberg, 61-105 (2015).

[13] G. Sobon, Photon. Res. 3 (2), A56-A63 (2015).

[14] W. Richter, H. Kohler, C.R. Becker, Phys. Status Solidi 84, 619628 (1977).

[15] G. Hao, X. Qi, Y. Fan, et al., Appl. Phys. Lett. 102, 013105 (2013).

[16] K.A. Kokh, V.V. Atuchin, T.A. Gavrilova, et al., Solid State Commun. 177, 16-19 (2014).

[17] S.M. Souza, D.M. Triches, J.C. De Lima, et al., Physica B 405, 2807-2817 (2010).

[18] S.D. Jackson, Nat. Photonics 6, 423-431 (2012). 